\title{
Patterns of risk for anxiety-depression amongst Vietnamese-immigrants: a comparison with source and host populations
}

Belinda J Liddell ${ }^{1,2^{*}}$, Tien Chey ${ }^{3}$, Derrick Silove ${ }^{1,3}$, Thuy Thi Bich Phan ${ }^{1,3}$, Nguyen Mong Giao ${ }^{4}$ and Zachary Steel ${ }^{1,3}$

\begin{abstract}
Background: Studies suggest that immigrants have higher rates of anxiety-depression than compatriots in low-middle income countries and lower rates than populations in host high income countries. Elucidating the factors that underlie these stepwise variations in prevalence may throw new light on the pathogenesis of anxietydepressive disorders globally. This study aimed to examine whether quantitative differences in exposure to, or the interaction between, risk factors account for these anxiety-depression prevalence differences amongst immigrant relative to source and host country populations.
\end{abstract}

Methods: Multistage population mental health surveys were conducted in three groups: 1) a Vietnameseimmigrant sample settled in Australia $(n=1161) ; 2)$ a Vietnamese source country sample residing in the Mekong Delta region ( $n=3039) ; 3)$ an Australian-born host country sample $(n=7964)$. Multivariable logistic regression analyses compared risk factors between the Vietnamese-immigrant group and: 1) the Mekong Delta Vietnamese; and 2) the Australian-born group. Twelve month anxiety-depression diagnoses were the main outcome measures, derived from the Composite International Diagnostic Interview (CIDI), supplemented by an indigenously derived measure - the Phan Vietnamese Psychiatric Scale (PVPS) in both Vietnamese groups.

Results: The 12-month prevalence of anxiety-depression showed a stepwise increase across groups: Mekong Delta Vietnamese 4.8\%; Vietnamese-immigrants 7.0\%; Australian-born 10.2\%. The two Vietnamese populations showed a similar risk profile with older age, exposure to potentially traumatic events (PTEs), multiple physical illnesses and substance use disorder (SUD) being associated with anxiety-depression, with the older Vietnamese-immigrants reporting greater exposure to these factors. The interaction between key risk factors differed fundamentally when comparing Vietnamese-immigrant and Australian-born samples. Age emerged as the major discriminator, with young Vietnamese-immigrants exhibiting particularly low rates of anxiety-depression.

Conclusions: The findings reported here suggest that core risk factors for anxiety-depression may be universal, but their patterning and interaction may differ according to country-of-origin. The study also highlights the importance of including both standard international and culturally-specific measures to index cross-cultural manifestations of common mental disorders.

Keywords: Anxiety, Depression, Risk factor, Immigrant, Low-middle income countries (LMIC), High income countries (HIC), Age, Trauma, Culture, Vietnam

\footnotetext{
* Correspondence: b.liddell@unsw.edu.au

'Psychiatry Research and Teaching Unit (PRTU), School of Psychiatry, University of New South Wales, Sydney, Australia

${ }^{2}$ School of Psychology, University of New South Wales, Sydney, Australia

Full list of author information is available at the end of the article
} 


\section{Background}

Recent national epidemiologic studies have demonstrated a wide variation in the prevalence of anxietydepression disorders across countries [1-3]. Comparing immigrant populations from low and middle income countries (LMIC), to compatriots in their country-oforigin and the host population in their country of resettlement (typically high income countries; HIC), offers the potential to develop a greater understanding of the factors contributing to these differences in prevalence rates. Past studies in this field have been undertaken almost exclusively in North America, the focus being on Mexican and Puerto Rican (LMIC) immigrants to the United States [4-6]. Immigrant populations have tended to display lower rates of anxiety-depression relative to the host society, and higher $[4,6]$ or comparable [5] rates to compatriots remaining in the source country. In the only study undertaken outside North America, the rate of anxiety-depression amongst Vietnamese immigrants was also found to be substantially lower than that of the host Australian-born population but higher than a Vietnamese source country sample [7]. The present analysis will extend the findings of our studies amongst Vietnamese populations to investigate for the first time the nature and possible interactions of risk factors in determining the variation in inter-population prevalence rates.

Certain demographic and psychosocial risk factors for anxiety-depression appear to be universal, in particular, female gender [8]; unemployment [9]; lower levels of education [10]; young (versus older) adulthood [11]; comorbid substance use disorder (SUD) [12,13]; physical ill-health [14]; exposure to potentially traumatic events (PTEs) [15]; and in relevant samples, exposure to refugee-specific experiences such as political persecution and forced displacement $[15,16]$. An important question addressed in the present study is how these universal risk factors contribute to variations in inter-country anxiety-depression prevalence rates. First, we will examine the extent to which inter-country anxiety-depression prevalence differences are associated with variation in the quantity of exposure to risks such as unemployment, poor general health and high levels of trauma exposure [17]. We will then further investigate whether there are ethno- specific risk factor patterns operating as a function of country-group [18]. For example age has been found to operate differently between Hispanic vs. nonHispanic groups in the United States, with older age being associated with mental disorder in the former group and younger age in the latter [19]. If different risk factor patterns can be established when comparing an immigrant group to their host and source country populations, it will point towards the need to consider possible ecological, cultural and biological differences that may account for the variation in anxiety-depression between populations born in different countries [2].

Ensuring the accurate measurement of anxietydepression across cultures remains a 'grand challenge' in global mental health [20]. There is growing recognition that standard diagnostic measures may be insensitive to culture-specific modes of experiencing and reporting psychiatric symptoms $[7,21]$. One strategy to address this challenge is to supplement standard diagnostic measures with indigenously-derived measures of anxiety-depression, an approach implemented in the present study. The disadvantage of adding a measure to the assessment of the source country and immigrant group (but not the host population) is outweighed by the risk of under-estimating the prevalence of disorders if only Western-derived measures are used [22].

The present analysis draws on three community mental health surveys administered amongst: 1) Vietnamese refugee-immigrants settled in New South Wales, Australia; 2) a Vietnamese source country sample residing in the Mekong-Delta region of Cần Thơ City and Hậu Giang Province; and 3) the general Australian-born host population [7]. The aim of the study was to compare the Vietnamese-immigrant group with the source and host samples in order to test whether (a) quantitative differences in risk factor profiles accounted for variation in anxiety-depression prevalence between the population groups; or (b) whether there are distinct interactions in risk factors based on country-of-origin or current residency.

\section{Methods}

\section{Sampling and procedure}

\section{Vietnamese-immigrant survey}

A multistage probability proportional to size (PPS) sampling methodology was applied to 44 census collection districts within 5 local government areas in New South Wales, Australia, resident to $75 \%$ of the state's Vietnamese population. All non-Vietnamese names in phonebook listings were eliminated prior to approaching remaining households $(n=6,264)$, initially by letter, followed by a visit from a Vietnamese-speaking interviewer. Within the 1, 413 dwellings identified as housing Vietnamese residents born in Vietnam, one adult respondent (aged over 18 years) was randomly invited for interview. Interviews were undertaken between June 1999 and May 2000, with the majority of interviews conducted in Vietnamese (98\%). The study was approved by the Human Research Ethics Committees at the University of Adelaide and University of New South Wales, Australia. The final sample comprised 1, 161 Vietnamese adults, representing an $82.6 \%$ response rate, and their average period of resettlement in Australia was 11 years. 


\section{Mekong Delta Vietnamese survey}

The survey was conducted between November 2004 and March 2005 in Cần Thơ City and Hậu Giang Province in the Mekong Delta region of Vietnam, comprising a mixed rural/urban population of approximately 2 million people. The survey applied a multistage probability cluster design. Population PPS sampling was applied to 31 hamlets (16 from 501 hamlets in Cần Thơ and 15 from 487 hamlets in Hậu Giang). Within each hamlet, a random commencement point was used to select 100 consecutive households, with a single adult respondent chosen for interview on the basis of age ranking using a randomized Kish grid (without replacements). The study was approved by the Human Research Ethics Committee at the University of New South Wales, Australia, and reviewed and approved by the Cần Thơ Health Service. The final sample comprised 3, 039 respondents from 3, 100 households (98\% response rate). All interviews were conducted in Vietnamese.

\section{Australian-born survey}

A national survey of mental health was conducted by the Australian Bureau of Statistics (ABS) in 1997, in which 10, 461 consenting adults (aged over 18 years) were interviewed in an Australian-wide stratified multistage probability sample of 13,624 private dwellings (78\% response rate). The present study is based on the interviews of the 7, 961 respondents born in Australia.

\section{Diagnostic Survey Instruments:}

In all three surveys, respondents were administered the mood, anxiety and SUD modules of the Composite International Diagnostic Interview (CIDI), version 2.0. The CIDI has been implemented globally [23] and is a lay-administered structured diagnostic interview assessing DSM-IV disorders $[24,25]$. The index used for the present study was the 12-month diagnosis of either a mood disorder (depression, dysthymia, mania, hypomania or bipolar disorder) and/or an anxiety disorder (generalized anxiety disorder, panic disorder, social phobia, agoraphobia, obsessive-compulsive disorder or posttraumatic stress disorder). The 12-month presence of a SUD, including alcohol/substance harmful use or dependence, was treated as a risk factor for anxietydepression in the regression analyses (see below).

Both Vietnamese samples completed the 12-month version of the Phan Vietnamese Psychiatric Scale (PVPS) [26]. The measure was developed by gathering indigenously derived expressions of psychological distress amongst Vietnamese populations and then subjecting the item pool to a series of psychometric analyses that yielded three sub-scales: a 26-item depression scale, a 13-item anxiety scale and a 14-item somatization scale $[26,27]$. Prior testing of the PVPS has demonstrated the instrument's reliability and validity: test-retest reliability was $r=0.89$ for the depression sub-scale, and $r=0.81$ for the anxiety sub-scale; internal consistency ranged from 0.93-0.95 for depression and 0.91-0.93 for anxiety [26]. The sub-scale cut-off thresholds were validated at: depression $\geq 1.85$; anxiety $\geq 1.45$. A previous study has demonstrated sound diagnostic concordance between the CIDI and PVPS for the Vietnamese-immigrant sample used in the present study (depression subscale: area under the curve $(\mathrm{AUC})=0.73,95 \%$ confidence interval (CI): 0.64-0.81; anxiety subscale: $\mathrm{AUC}=0.71$ (95\% CI: 0.64-0.79) [7]. A lower level of diagnostic concordance was demonstrated for the Mekong Delta Vietnamese sample (depression subscale: AUC $=0.65$ [95\% CI: 0.560.73]; anxiety subscale: $\mathrm{AUC}=0.64$ [95\% CI: 0.59-0.7]. In both groups, the PVPS identified the majority of CIDI cases (particularly in the Vietnamese-immigrant sample) but also detected a substantial number of additional cases [7]. Further, the PVPS identified a similar prevalence rate of anxiety-depression across the two Vietnamese samples, whereas the CIDI detected substantially more cases amongst the immigrant than the source country group [7]. PVPS cases also demonstrated similar levels of disability as CIDI-detected cases in both Vietnamese groups, suggesting that the PVPS did not identify persons with a milder level of disturbance [7]. These observations indicate that the CIDI may lack sensitivity in identifying the full range of cases of anxiety-depression amongst Vietnamese populations, particularly in those living in the home country. Hence, to ensure comprehensive coverage of cases of anxiety-depression, we included both CIDI and PVPS cases in examining risk factor profiles amongst the two Vietnamese samples.

PTE exposure was measured by the Traumatic Events Screen (CIDI 2.0 PTSD module), with 14 additional items included from the Harvard Trauma Questionnaire [28] in the Vietnamese surveys due to the particular relevance of these items to the trauma history of Southeast Asian refugees. The HTQ trauma events were mapped onto the CIDI trauma categories to allow for quantitative comparisons between Australian and Vietnamese samples [29].

A common list of medical conditions was included in all surveys covering a range of 12 serious physical health states, including circulatory and endocrine diseases to index general physical health [30].

\section{Translation}

The CIDI was translated into Vietnamese using common translation and blind back-translation methods [31]. Minor language modifications were made to account for small idiom differences between Vietnamese-immigrants and their compatriots living in the Mekong Delta [7]. All three surveys were administered by trained interviewers 
using prompt cards and on-site computer-assisted personalized interview (CAPI) technology.

\section{Statistical analyses \\ Data preparation}

Statistical analyses were conducted using SAS version 9.1.3 (SAS Institute Inc., Cary, NC, USA). The three samples were weighted according to the age and sex distribution of their respective base populations using national census data. This was conducted to reflect the population socio-demographic characteristics at the time of the survey, taking into account the probability of being sampled and the differential response across the population.

Each sample was stratified according to three age bands: young adults (18-29 years); mid-age adults (3044 years) and older adults (45+ years), broadly reflective of the probability of being exposed to trauma during the war in Vietnam: the young group would not have been directly exposed; the mid-age group may have been exposed as children; and the older group would have lived through the war as adults.

Other demographic factors examined were: employment (2 categories: "Paid employment/home duties" as the reference group, inclusive of paid employment, active home duties and being a pensioner/too sick to work; and "Unemployed" inclusive of those unemployed and actively seeking paid employment); education (3 categories; "not completed high school", "completed high school" and "university or vocational training" the later serving as the reference group). We derived three levels of exposure to PTEs: 0 PTEs (no exposure as the reference group); 1-2 PTE types (low exposure); 3 or more PTE types (high exposure) [29]. Medical condition responses were analyzed to provide a composite account of the number of illnesses reported: none (reference group); 1 medical condition; 2 or more medical conditions. Substance use disorder (SUD) was indexed according to two categories (diagnosis present or absent, the later serving as the reference group).

\section{Data analysis}

A diagnosis for either mood or anxiety disorder was derived from the CIDI for the Australian-born population, and from the combined CIDI and/or PVPS for both Vietnamese populations. The PVPS sub-scale thresholds used were: depression $\geq 1.85$; anxiety $\geq 1.45$.

Chi-square analyses were first conducted to examine differences between population groups within each demographic factor $(\mathrm{p}<.05)$.

Two multivariable logistic regression analyses were then conducted to examine the association between risk factors and anxiety-depression diagnoses: the first between the Vietnamese-immigrant and the Mekong Delta
Vietnamese samples, and the second, comparing the Vietnamese-immigrant group with the Australian-born sample. The purpose of these analyses was to examine whether quantitative differences in risk factors accounted for variations in prevalence rates across samples or whether country-of-origin influenced the pattern of risk factors and their interaction. Common risk factors active in all three population groups were included in the model, specifically age, sex, employment status, PTE exposure, medical conditions and SUD. Predictors were tested in three ways: as main effect factors, as 2-way interactions by population group; and higher-order 3-way interactions with population group and age. Reference groups were held constant for both analyses with the exception of age in order to ensure odd ratios fell within the +1 range for age-related interactions between population groups.

Missing values constituted less than $2 \%$ of the data in Analysis 1 (Vietnamese-immigrant/Mekong Delta Vietnamese samples), and these participants were excluded from the model. There were no missing values in Analysis 2 (Vietnamese-immigrant/Australian-born samples). We commenced with the full model in which all risk factors and interaction terms were examined. Nonsignificant variables $(\mathrm{p}>0.05)$ were then iteratively removed in order to refine the final model. Odds ratios (OR) with 95\% confidence intervals were used to interpret significant main effects if there were no statistically significant interaction terms. Significant interaction effects were interpreted by reference to prevalence estimates and post-hoc chisquare analyses. The c-statistic was used as a measure of the accuracy of prediction in the final models with values between 0.7 and 0.8 indicating a good fit to the data [32].

\section{Results}

\section{Demographic characteristics}

The socio-demographic characteristics of the three populations are presented in Table 1 . The gender distribution was similar across groups $\left(\chi^{2}(2)=1.9, \mathrm{p}<.38\right)$. The Vietnamese samples were significantly younger $\left(x^{2}(4)=334.2, p<.0001\right)$, had a lower level of tertiary or equivalent education $\left(X^{2}(4)=239.5, \mathrm{p}<.0001\right)$ and a higher rate of unemployment $\left(\chi^{2}(2)=117.9, p<.0001\right)$ than the Australian-born group. The 12-month prevalence of anxiety-depression based on the combined index of CIDI and PVPS cases was 7.0\% (95\% CI: 5.5\% $8.5 \%)$ for the Vietnamese-immigrant group and $4.8 \%$ (95\% CI: 4.0\% - 5.6\%) for the Mekong Delta Vietnamese. The rate of anxiety-depression amongst the Australianborn was the highest at 10.2\% (95\% CI: 9.5\% - 10.9\%) based on CIDI-only diagnoses.

\section{Multivariable logistic regression analyses}

The two multivariable logistic regression models presented in Table 2 yielded c-statistics indicating a 
Table 1 Sociodemographic characteristics of population groups

\begin{tabular}{|c|c|c|c|c|c|c|c|c|c|c|}
\hline & \multicolumn{3}{|c|}{ Vietnamese-immigrants } & \multicolumn{3}{|c|}{ Mekong Delta Vietnamese } & \multicolumn{3}{|c|}{ Australian-born } & \multirow[b]{2}{*}{$\begin{array}{l}\text { Chi-square } \\
\text { group } \\
\text { differences }\end{array}$} \\
\hline & Number & $\%$ & $\begin{array}{l}\% \text { estimated } \\
\text { prevalence of } \\
\text { anxiety- } \\
\text { depression }\end{array}$ & Number & $\%$ & $\begin{array}{l}\text { \% estimated } \\
\text { prevalence of } \\
\text { anxiety- } \\
\text { depression }\end{array}$ & Number & $\%$ & $\begin{array}{l}\text { \% estimated } \\
\text { prevalence of } \\
\text { anxiety- } \\
\text { depression }\end{array}$ & \\
\hline \multicolumn{11}{|l|}{ Overall } \\
\hline $\begin{array}{l}\text { Total for } \\
\text { population } \\
\text { group }\end{array}$ & 1161 & $100 \%$ & $7.0 \%$ & 3039 & $100 \%$ & $4.8 \%$ & 7961 & $100.0 \%$ & $10.2 \%$ & \\
\hline \multicolumn{11}{|l|}{ Gender } \\
\hline Male & 572 & $49.3 \%$ & $5.9 \%$ & 1431 & $47.1 \%$ & $3.5 \%$ & 3839 & $48.2 \%$ & $7.8 \%$ & \multirow{2}{*}{$\begin{array}{c}x^{2}(2)=1.9 \\
p<.38\end{array}$} \\
\hline Female & 589 & $50.7 \%$ & $8.1 \%$ & 1608 & $52.9 \%$ & $6.1 \%$ & 4122 & $51.8 \%$ & $12.4 \%$ & \\
\hline \multicolumn{11}{|l|}{ Age } \\
\hline 18-29 year & 371 & $26.9 \%$ & $2.0 \%$ & 1203 & $39.6 \%$ & $3.1 \%$ & 2152 & $27.0 \%$ & $11.7 \%$ & \multirow{3}{*}{$\begin{array}{c}x^{2}(4)=334.3 \\
p<.0001\end{array}$} \\
\hline $30-44$ years & 493 & $42.4 \%$ & $8.6 \%$ & 1020 & $33.5 \%$ & $3.9 \%$ & 2469 & $31.0 \%$ & $12.7 \%$ & \\
\hline $45+$ years & 297 & $25.6 \%$ & $10.4 \%$ & 816 & $26.9 \%$ & $8.5 \%$ & 3340 & $42.0 \%$ & $7.4 \%$ & \\
\hline \multicolumn{11}{|l|}{ Marital Status } \\
\hline Married & 741 & $63.8 \%$ & $6.7 \%$ & 2153 & $70.8 \%$ & $5.3 \%$ & 5038 & $63.3 \%$ & $8.3 \%$ & \multirow{2}{*}{$\begin{array}{c}x^{2}(2)=56.7 \\
p<.0001\end{array}$} \\
\hline Not married & 420 & $36.2 \%$ & $7.2 \%$ & 886 & $29.1 \%$ & $3.6 \%$ & 2923 & $36.7 \%$ & $13.4 \%$ & \\
\hline \multicolumn{11}{|l|}{ Education } \\
\hline $\begin{array}{l}\text { Not } \\
\text { completed } \\
\text { high school }\end{array}$ & 689 & $59.4 \%$ & $7.5 \%$ & 1937 & $63.8 \%$ & $5.1 \%$ & 4668 & $58.6 \%$ & $10.9 \%$ & \multirow[t]{3}{*}{$\begin{array}{c}x^{2}(4)=239.5 \\
p<.0001\end{array}$} \\
\hline $\begin{array}{l}\text { Completed } \\
\text { high school }\end{array}$ & 217 & $18.7 \%$ & $5.0 \%$ & 675 & $22.2 \%$ & $5.6 \%$ & 1179 & $14.8 \%$ & $9.8 \%$ & \\
\hline $\begin{array}{l}\text { University/ } \\
\text { vocational } \\
\text { training }\end{array}$ & 255 & $22.0 \%$ & $5.8 \%$ & 426 & $14.0 \%$ & $2.3 \%$ & 2113 & $26.5 \%$ & $8.8 \%$ & \\
\hline \multicolumn{11}{|l|}{ Employment } \\
\hline $\begin{array}{l}\text { Paid } \\
\text { employment/ } \\
\text { home duties }\end{array}$ & 1070 & $92.1 \%$ & $6.7 \%$ & 2763 & $90.9 \%$ & $4.4 \%$ & 7638 & $95.9 \%$ & $9.7 \%$ & \multirow[t]{2}{*}{$\begin{array}{c}x^{2}(2)=117.9 \\
p<.0001\end{array}$} \\
\hline Unemployed & 91 & $7.9 \%$ & $10.4 \%$ & 276 & $9.1 \%$ & $8.3 \%$ & 323 & $4.1 \%$ & $20.8 \%$ & \\
\hline \multicolumn{11}{|l|}{ PTE exposure } \\
\hline No PTE & 492 & $42.4 \%$ & $3.9 \%$ & 2568 & $84.5 \%$ & $3.9 \%$ & 3457 & $43.4 \%$ & $6.8 \%$ & \multirow{3}{*}{$\begin{array}{c}x^{2}(4)=1666.5 \\
p<.0001\end{array}$} \\
\hline $\begin{array}{l}1-2 \text { PTEs } \\
\text { reported }\end{array}$ & 401 & $34.6 \%$ & $6.3 \%$ & 404 & $13.3 \%$ & $8.8 \%$ & 3248 & $40.8 \%$ & $10.0 \%$ & \\
\hline $\begin{array}{l}3 \text { or more } \\
\text { PTEs reported }\end{array}$ & 267 & $23.0 \%$ & $13.6 \%$ & 67 & $2.2 \%$ & $18.5 \%$ & 1257 & $15.8 \%$ & $20.1 \%$ & \\
\hline \multicolumn{11}{|l|}{$\begin{array}{l}\text { Substance Use } \\
\text { Disorder }\end{array}$} \\
\hline $\begin{array}{l}\text { Negative } \\
\text { diagnosis }\end{array}$ & 1142 & $98.4 \%$ & $6.8 \%$ & 3004 & $98.9 \%$ & $4.8 \%$ & 7262 & $91.2 \%$ & $8.6 \%$ & \multirow[t]{2}{*}{$\begin{array}{c}x^{2}(2)=271.7 \\
p<.0001\end{array}$} \\
\hline $\begin{array}{l}\text { Positive } \\
\text { diagnosis }\end{array}$ & 19 & $1.6 \%$ & $17.2 \%$ & 34 & $1.1 \%$ & $12.6 \%$ & 699 & $8.8 \%$ & $26.3 \%$ & \\
\hline \multicolumn{11}{|c|}{$\begin{array}{l}\text { Number of self-reported } \\
\text { medical conditions }\end{array}$} \\
\hline None & 851 & $73.3 \%$ & $4.5 \%$ & 2161 & $71.1 \%$ & $3.1 \%$ & 4860 & $61.0 \%$ & $9.0 \%$ & \multirow{3}{*}{$\begin{array}{c}x^{2}(4)=239.5 \\
p<.0001\end{array}$} \\
\hline 1 condition & 214 & $18.4 \%$ & $10.9 \%$ & 697 & $22.9 \%$ & $7.1 \%$ & 1886 & $23.7 \%$ & $10.9 \%$ & \\
\hline $\begin{array}{l}2 \text { or more } \\
\text { conditions }\end{array}$ & 96 & $8.3 \%$ & $20.3 \%$ & 181 & $5.9 \%$ & $17.0 \%$ & 1215 & $15.3 \%$ & $13.7 \%$ & \\
\hline
\end{tabular}

Number and \% within each demographic variable and weighted prevalence estimates of anxiety-depression (\%) for the Vietnamese-immigrant, Mekong Delta Vietnamese and Australian-born populations. Demographic differences between population groups are indicated for each variable category by Chi-square analyses in the right column. 
Table 2 The final reduced multivariable logistic regression models

\begin{tabular}{|c|c|c|c|c|c|c|c|c|c|c|}
\hline \multirow[b]{2}{*}{ Predictor variables } & \multicolumn{5}{|c|}{$\begin{array}{l}\text { 1. Vietnamese-immigrant/Mekong } \\
\text { Delta Vietnamese Final Model }\end{array}$} & \multicolumn{5}{|c|}{$\begin{array}{l}\text { 2. Vietnamese-immigrants/Australian- } \\
\text { born Final Model }\end{array}$} \\
\hline & df & $\begin{array}{l}\text { Wald Chi- } \\
\text { Square }\end{array}$ & $p$ value & OR & $95 \%$ C.I. & df & $\begin{array}{l}\text { Wald Chi- } \\
\text { Square }\end{array}$ & $\begin{array}{c}p \\
\text { value }\end{array}$ & OR & 95\% C.I. \\
\hline \multicolumn{11}{|l|}{ Main effects } \\
\hline Female (Reference: Male) & 1 & 20.12 & $<.000$ & 2.0 & $1.5-2.7$ & 1 & 109.40 & $<.000$ & 2.3 & $1.9-2.7$ \\
\hline $\begin{array}{l}\text { Unemployment } \\
\text { (Reference: Paid Employment) }\end{array}$ & 1 & 15.19 & $<.000$ & 2.3 & $1.5-3.5$ & 1 & 19.10 & $<.000$ & 1.8 & $1.4-2.4$ \\
\hline $\begin{array}{l}\text { Substance Use Disorder } \\
\text { (Reference: No SUD) }\end{array}$ & 1 & 9.66 & $<.000$ & 4.0 & $1.7-9.6$ & 1 & 134.01 & $<.000$ & 3.5 & $1.8-6.8$ \\
\hline \multicolumn{11}{|l|}{ PTE (Reference: 0 PTE) } \\
\hline 1-2 PTEs & 1 & 0.00 & 0.959 & 1.0 & $0.8-1.3$ & 1 & 5.42 & 0.020 & 0.9 & $0.2-3.0$ \\
\hline 3+ PTES & 1 & 19.58 & $<.000$ & 2.0 & $1.7-2.3$ & 1 & 137.12 & $<.000$ & 1.9 & $1.6-2.3$ \\
\hline \multicolumn{11}{|l|}{ Age group } \\
\hline Age: $18-29$ years & 1 & 4.64 & 0.031 & 0.6 & $0.4-1.0$ & Reference & & & 1.0 & \\
\hline Age: $30-44$ years & Reference & & & 1.0 & & 1 & 15.06 & $<.000$ & 1.4 & $1.2-1.7$ \\
\hline Age: $45+$ years & 1 & 0.21 & 0.650 & 0.9 & $0.6-1.3$ & 1 & 0.27 & 0.601 & 0.9 & $0.8-1.2$ \\
\hline \multicolumn{11}{|l|}{$\begin{array}{l}\text { Number of medical conditions } \\
\text { (Reference: } 0 \text { medical conditions) }\end{array}$} \\
\hline Medical conditions: 1 condition & 1 & 0.16 & 0.686 & 1.9 & $1.3-2.6$ & 1 & 0.58 & 0.445 & 1.0 & $0.7-1.2$ \\
\hline $\begin{array}{l}\text { Medical conditions: } 2 \text { or more } \\
\text { conditions }\end{array}$ & 1 & 30.54 & $<.000$ & 3.9 & $2.6-5.9$ & 1 & 36.81 & $<.000$ & 2.2 & $1.8-2.7$ \\
\hline $\begin{array}{l}\text { Population group } \\
\text { (Ref: Vietnamese-immigrant) }\end{array}$ & & 5.65 & 0.017 & 1.3 & $1.0-1.6$ & 1 & 14.52 & $<.000$ & 1.3 & $1.1-1.5$ \\
\hline \multicolumn{11}{|l|}{ Interaction effects } \\
\hline Population group by Age & 2 & 8.86 & 0.012 & & & 2 & 18.90 & $<.000$ & & \\
\hline \multirow[t]{2}{*}{$\begin{array}{l}\text { Population group by Age } \\
\text { by PTE exposure }\end{array}$} & 4 & 7.53 & 0.110 & & & 4 & 12.29 & 0.015 & & \\
\hline & & & & & & 2 & 14.99 & $<.001$ & & \\
\hline
\end{tabular}

Presented are the final reduced multivariable logistic regression models for Analysis 1: Vietnamese-immigrant/Mekong Delta Vietnamese; Analysis 2: Vietnameseimmigrant/Australian-born. Both main and interaction effects are included, with reference group indicated in the left column where applicable. Interpreting findings at the main effect level must be treated with caution in the presence of a significant interaction effect (indicated by italicized OR and $95 \%$ C.I. indices). Note: different reference groups are used for the age variable between analysis 1 and 2 .

moderate to good level of prediction (Vietnamese-immigrant/ Mekong Delta Vietnamese analysis 1: c $=0.723$; Vietnameseimmigrant/Australian-born analysis 2: $\mathrm{c}=0.743$ ). Nonsignificant interaction terms (population group by sex, employment and medical disorder respectively) were excluded from the final modeling.

Main effect risk factors common to all three populations Being female and being unemployed emerged as risk factors common to all populations in both models, with each of these individual factors doubling the odds for having an anxiety-depression diagnosis. The presence of more than one medical condition was associated with a four-fold increase in odds in the Vietnamese-immigrant/Mekong Delta model, and a twofold increase in the Vietnamese-immigrant/Australian-born model (Table 2).
The highest category of PTE exposure (3 or more PTE categories) was a significant risk factor as a main effect in the analysis involving the Vietnamese samples ( $\mathrm{p}<.0001$; analysis 1$)$, doubling the odds for anxietydepression. There was a substantial difference between the Vietnamese samples in the proportion falling within the high PTE exposure category: $23 \%$ of the Vietnameseimmigrant group compared to $2.2 \%$ of the Mekong Delta sample $\left(\chi^{2}(1)=496.2, p<.000\right)$. PTE exposure was also associated with increased risk for anxiety-depression in analysis 2, but significantly interacted with population and age (see below). The prevalence of SUDs was low amongst both Vietnamese groups relative to the Australian-born sample (Vietnamese-immigrants: 1.6\%; Mekong Delta Vietnamese: 1.1\%; Australian-born: 8.8\%). Nevertheless, a comorbid SUD diagnosis emerged as a significant risk factor as a main effect for the Vietnamese 
in both settings (analysis 1 ), increasing the odds by a factor of 4 for anxiety-depression.

\section{Interaction Effects}

\section{Population by age}

A significant interaction between population group and age was evident in both regression analyses (Table 2) but the pattern differed according to the population under consideration (prevalence rates by age are presented in Table 1). The risk for anxiety-depression increased with age in both Vietnamese populations (analysis 1), with particularly high rates of anxiety-depression in the oldest age groups. The pattern of increased prevalence emerged at an earlier age amongst the Vietnamese-immigrants, with the 30-44 year group showing greater risk (8.6\%) than their Mekong Delta Vietnamese counterparts in the same age band $\left(3.9 \%: \chi^{2}(1)=13.7, \mathrm{p}<.000\right)$.

When comparing immigrants with the host sample (analysis 2), there was a trend for older Vietnamese-immigrants to show a greater prevalence of anxiety-depression (10.4\%) than older Australians $\left(7.4 \% ; \chi^{2}(1)=3.58, p=.059\right)$. There was a notable reversal of that pattern for both the midage band (Vietnamese-immigrants: 8.6\%; Australian-born: $\left.12.7 \% ; \chi^{2}(1)=6.58, p=.009\right)$, and a pronounced difference for the youngest age group (Vietnamese-immigrants: 2.0\%; Australian-born: $11.7 \% ; \chi^{2}(1)=6.47, \mathrm{p}=.01$ ).

\section{Population by age by PTE exposure}

In the Vietnamese-immigrant/Australian-born model (analysis 2), a significant 3-way interaction emerged for population group by age by PTE exposure $(\mathrm{p}=0.015$; Table 2; prevalence rates by age and PTE exposure are displayed in Table 3). High PTE exposure posed a large and similar risk for anxiety-depression for older Australian and older Vietnamese-immigrants (Vietnamese-immigrants: 16.4\%; Australian-born: 16\%). Nonetheless, a substantially larger proportion of the Vietnamese-immigrants fell into the high PTE class (42.9\%, compared to their Australian-born counterparts, $\left.16.1 \% ; \chi^{2}(1)=133.7, p<.000\right)$, accounting in part for the overall higher prevalence of anxiety-depression in older Vietnamese. For the 30-44 year age band, anxietydepression prevalence for Vietnamese-immigrants was half that of the Australian-born group (Vietnameseimmigrants: $13.7 \%$; Australian-born: $22.9 \% ; \chi^{2}(1)=4.2$, $\mathrm{p}=.041)$, despite a greater portion of Vietnamese-

Table 3 Presents disaggregated for significant interaction effects in analysis 2

\begin{tabular}{|c|c|c|c|c|c|c|c|c|c|}
\hline & \multicolumn{3}{|c|}{ Age: $18-29$ years } & \multicolumn{3}{|c|}{ Age: $30-44$ years } & \multicolumn{3}{|c|}{ Age: $45+$ years } \\
\hline & Number & $\begin{array}{l}\% \text { within } \\
\text { age sample }\end{array}$ & $\begin{array}{c}\% \\
\text { prevalence } \\
\text { of anxiety- } \\
\text { depression }\end{array}$ & Number & $\begin{array}{l}\% \text { within } \\
\text { age sample }\end{array}$ & $\begin{array}{c}\% \\
\text { prevalence } \\
\text { of anxiety- } \\
\text { depression }\end{array}$ & Number & $\begin{array}{l}\text { \% within } \\
\text { age sample }\end{array}$ & $\begin{array}{c}\% \\
\text { prevalence } \\
\text { of anxiety- } \\
\text { depression }\end{array}$ \\
\hline \multicolumn{10}{|c|}{$\begin{array}{l}\text { Significant interaction terms analysis 2: } \\
\text { Vietnamese-immigrant/Australian-born }\end{array}$} \\
\hline \multicolumn{10}{|l|}{ PTE exposure } \\
\hline \multicolumn{10}{|l|}{$\begin{array}{l}\text { Vietnamese-immigrant } \\
\text { group }\end{array}$} \\
\hline High PTE exposure & 26 & $7.1 \%$ & $0.0 \%$ & 114 & $23.0 \%$ & $13.7 \%$ & 128 & $42.9 \%$ & $16.4 \%$ \\
\hline Low PTE exposure & 116 & $31.1 \%$ & $1.8 \%$ & 198 & $40.1 \%$ & $9.5 \%$ & 88 & $29.6 \%$ & $5.1 \%$ \\
\hline No PTE exposure & 229 & $61.8 \%$ & $2.4 \%$ & 182 & $36.8 \%$ & $4.5 \%$ & 82 & $27.5 \%$ & $6.8 \%$ \\
\hline \multicolumn{10}{|l|}{ Australian-born group } \\
\hline High PTE exposure & 300 & $13.9 \%$ & $23.3 \%$ & 421 & $17.1 \%$ & $22.9 \%$ & 536 & $16.1 \%$ & $16.0 \%$ \\
\hline Low PTE exposure & 828 & $38.5 \%$ & $14.1 \%$ & 1027 & $41.6 \%$ & $11.7 \%$ & 1392 & $41.7 \%$ & $6.3 \%$ \\
\hline No PTE exposure & 1025 & $47.6 \%$ & $6.3 \%$ & 1021 & $41.3 \%$ & $9.4 \%$ & 1411 & $42.3 \%$ & $5.3 \%$ \\
\hline \multicolumn{10}{|l|}{$\begin{array}{l}\text { Substance use } \\
\text { disorder (SUD) }\end{array}$} \\
\hline \multicolumn{10}{|l|}{$\begin{array}{l}\text { Vietnamese-immigrant } \\
\text { group }\end{array}$} \\
\hline SUD diagnosis & 9 & $2.3 \%$ & $0.0 \%$ & 6 & $1.2 \%$ & $27.6 \%$ & 4 & $1.3 \%$ & $38.3 \%$ \\
\hline No SUD diagnosis & 362 & $97.7 \%$ & $2.1 \%$ & 487 & $98.8 \%$ & $8.4 \%$ & 293 & $98.7 \%$ & $10.0 \%$ \\
\hline \multicolumn{10}{|l|}{ Australian-born group } \\
\hline SUD diagnosis & 360 & $16.7 \%$ & $20.9 \%$ & 236 & $9.6 \%$ & $32.2 \%$ & 103 & $3.1 \%$ & $31.6 \%$ \\
\hline No SUD diagnosis & 1792 & $83.3 \%$ & $9.8 \%$ & 2233 & $90.4 \%$ & $10.5 \%$ & 3237 & $96.9 \%$ & $6.7 \%$ \\
\hline
\end{tabular}


immigrants reporting high PTE exposure $23.0 \%$, compared to the Australian-born sample $17.1 \% ; \chi^{2}(1)=10.2$, $\mathrm{p}<.001)$. Fewer young Vietnamese-immigrants reported high-PTE exposure (7.1\%) compared to the young Australian born group $\left(13.9 \% ; \chi^{2}(1)=13.1, p<.000\right)$. The young adult Vietnamese-immigrant sample exhibited no association between high PTE exposure and anxietydepression, whereas the typical dose-response association held for the young Australian-born cohort (23.3\%; see Table 3). These differences by age and PTE exposure across population groups are displayed in Figure 1.

\section{Population by age by substance use disorder}

There was a significant interaction of SUD and age for anxiety-depression when comparing the Vietnameseimmigrant and Australian-born groups (analysis 2: population group by age by SUD interaction: $\mathrm{p}<.001$; Table 2 , prevalence rates Table 3). SUD was not associated with anxiety-depression amongst young Vietnamese-immigrants but incurred a considerable risk amongst the young Australian-born (20.9\%). In older age groups, similar associations between SUD and odds for anxiety-depression in both samples were observed: for instance, prevalence was $38.8 \%$ in the older Vietnamese-immigrant sample and $31.6 \%$ in the older Australian-born group.

\section{CIDI-only anxiety-depression cases in the Vietnamese samples}

To test whether the addition of the PVPS biased the findings for the Vietnamese samples, we repeated the key analysis for age using the CIDI results alone, a procedure that necessitated the pooling of both Vietnamese groups to achieve adequate statistical power. The results confirmed the pattern for the combined CIDI-PVPS findings, namely that younger adult Vietnamese $(0.8 \%$ in the 18-29 year group) had a lower prevalence rate of anxiety-depression than the older categories $(2.9 \%$ in the $30-44$ year age group; $2.0 \%$ in the $45+$ year age group).

\section{Discussion}

Our study aimed to examine factors underlying the consistent stepwise anxiety-depression prevalence rate patterns across host country populations (highest rates), resettled immigrant groups (intermediate rates) and source country populations (lowest rates). The findings provide evidence that risk factors vary not only in quantity between populations, but in their interaction based on the country-of-origin of the population. Risk factor profiles were similar between the Vietnamese-immigrant sample and the source Vietnamese population; but there were differences in the interaction of risk factors when comparing the Vietnamese-immigrant and the Australian-born samples. An analogous pattern has been observed for cross-national suicide rates, in which prevalence rates are largely constant between immigrants and their source country populations, but differ from those of the host society [33].

Risk factors that were common to all populations included being female, unemployment, and having poor physical health, an observation that supports the universal importance of these influences. The two Vietnamese populations showed consistency in their risk factor profiles (analysis 1), with the differences being entirely quantitative in nature. Specifically, older Vietnameseimmigrants showed higher rates of PTE exposure, number of medical conditions and SUD diagnoses than their Mekong Delta compatriots - risk factors that in concert exerted a greater burden of anxiety-depression in that group. The pattern for PTE exposure is consistent with the general dose-response relationship with anxiety-depression disorders observed in other studies amongst refugee groups exposed to war and

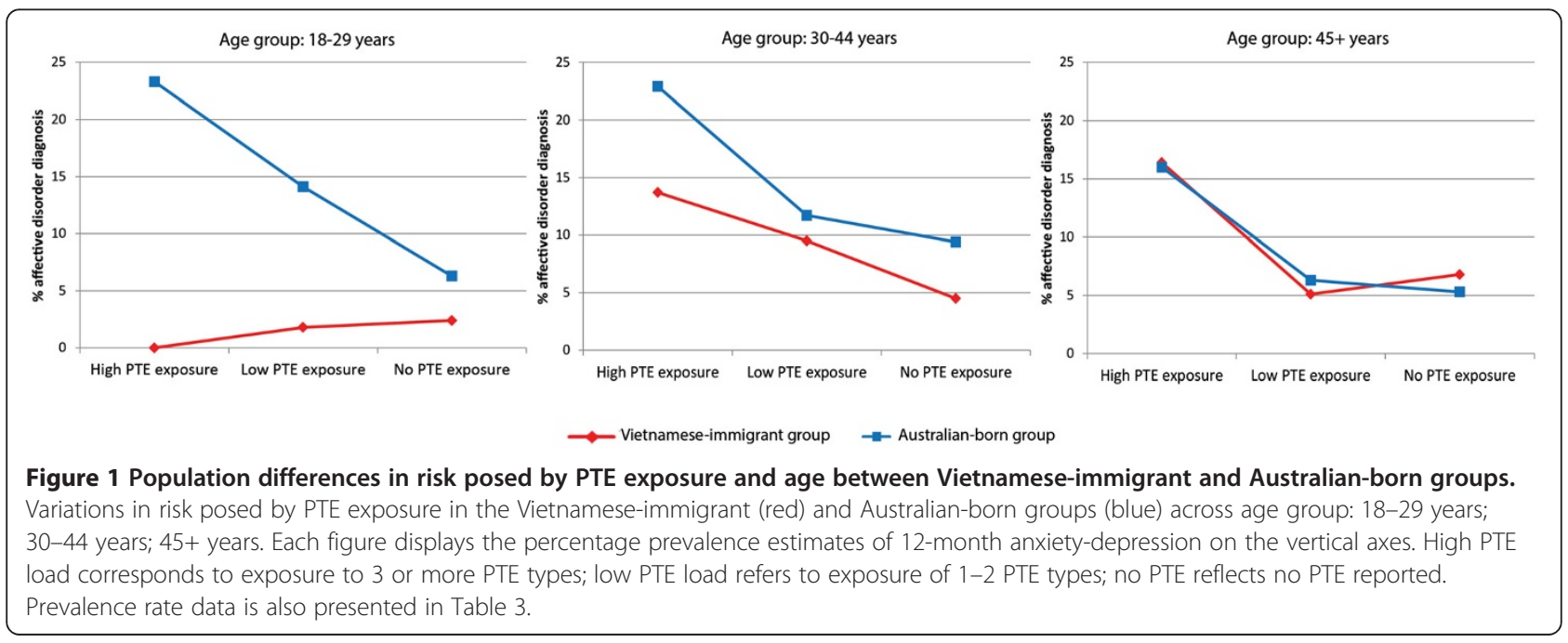


displacement traumas, including those involved in the Southeast Asian conflicts during the 1960-70s $[15,16,34,35]$. The higher rates of physical illness and SUD amongst older Vietnamese-immigrants may reflect the effects of exposure to war and the stress of forced migration.

In contrast, there was a marked difference in the pattern and interaction of risk factors between the Vietnamese-immigrant and Australian-born samples (Analysis 2). Age emerged as the key discriminator: the older cohort demonstrated higher rates of anxietydepression in the Vietnamese-immigrant group; whereas the youngest cohort exhibited the greatest risk for anxiety-depression in the Australian-born sample. Older age also posed a greater risk in the Mekong Delta Vietnamese group (analysis 1). This contrast in age risk between both Vietnamese and Australian-born populations is consistent with other data from LMIC and HIC countries $[11,36,37]$, a finding that appears to be independent of the impact of medical disorders with advancing age [36,37]. It is vital therefore to explore further why age exerts such a powerful but variable influence on the prevalence of anxiety-depression across countries [36].

PTE exposure was low and showed no association with anxiety-depression amongst young Vietnamese-immigrant adults, in contrast to the findings for the older Vietnamese-immigrants who were highly exposed to conflict-related trauma [26]. Young Vietnamese-immigrants differed markedly from the young Australianborn cohort who reported higher levels of PTEs and showed greater vulnerability to their impact in relation to risk of anxiety-depression. It is possible that specific factors not measured in our study act to protect younger Vietnamese-immigrants from anxiety-depression, including greater constraints on the activities of young adults, a greater level of social interdependence and high levels of familial support [38,39]. These social factors may protect young adults from encountering traumas in the first instance, and buffer those who are exposed against any deleterious emotional impact. Young Vietnameseimmigrants may also be protected against developing SUDs by virtue of the same cultural protective influences, a possibility that is supported by other studies amongst young Asian immigrant samples [40].

The present study adds important information to the debate regarding the universality or otherwise of the symptoms and determinants of common mental disorders such as anxiety-depression. Proponents of a universalistic position assert that disorders such as anxiety-depression are comparable across cultures, differing only in their surface manifestations [2]. The opposing position holds that the origins and nature of disorders vary fundamentally across cultures and contexts [41-43]. The findings reported here suggest that core risk factors may be universal, but their patterning and interaction may differ fundamentally across cultural and population groups. The findings also offer support to recent commentaries focusing on the diagnostic revisions in preparation for DSM-V, by demonstrating the importance of including culturally sensitive measures in assessing anxiety-depression disorders at a global level $[18,21,44]$. Although adding an indigenous measure means that assessment protocols are not strictly commensurable across cultures, this strategy offers the advantage of ensuring that prevalence rates are not under-estimated through using only Western-derived measures, particularly amongst populations from East Asia $[22,44]$. Our indigenous measure showed a moderate level of concordance with the CIDI amongst the Vietnamese-immigrants, but at the same time identified cases not detected by that measure [7]. Additionally, the risk associated with age remained consistent when the analysis was based on only CIDI diagnoses for the combined Vietnamese sample. Overall, the findings point to the value of combining indigenous and international diagnostic measures in transcultural comparative studies of this type.

Limitations of the study need to be acknowledged. First, the Mekong Delta represents just one region in a culturally diverse Vietnam; the site was selected because most Vietnamese-immigrants in Australia originate from the south of Vietnam. There would be benefit in replicating the findings in a nationally representative sample. There was a difference in the timing of the surveys forming the basis of the current analysis, with the Mekong Delta survey being undertaken more recently. We note, however, that if there was a process of secular shift, it would presumably have lessened differences between Vietnamese-immigrants and the Mekong Delta Vietnamese samples because of the recent acceleration of Westernization in Vietnam. Although response rates were high across all three samples, variation in participation may have influenced the proportion in each sample with and without anxiety-depressive disorders.

It was not possible to assess the specific impact of culture and migration experiences since these factors were only relevant to one group, the Vietnameseimmigrants. Clinical recalibration of the CIDI with other DSM-IV-based diagnostic instruments was not undertaken in the surveys included in the current analysis limiting definitive statements about the validity of the CIDI in assessing DSM-IV diagnoses in these populations. Studies undertaken among East Asian populations, including neighboring China, have identified adequate concordance between the CIDI and measures such as the Structured Clinical Interview for DSM-IV in settings despite recording similarly low prevalence estimates [22]. 


\section{Conclusions}

The findings suggest that country-of-origin may exert a powerful impact on the interaction of common risk factors associated with anxiety-depression, an effect that persisted in the immigrant group even though it had resided in the host society for more than a decade. Further pursuit of this theme may throw important light on the origins and pathogenesis of anxiety-depressive disorders, and their expression and prevalence internationally. Age of risk is of particular importance, an issue worthy of further study given that there is evidence of a diametrically different pattern across populations from LMIC and HICs. In particular, if it is possible to determine why young adults from LMICs have such a low prevalence of anxiety-depression, that knowledge could be translated into improving prevention and intervention strategies for young adults in HICs who are at higher risk of developing these disorders.

\section{Competing interests}

The authors report no competing interests.

\section{Authors' contributions}

$B J L$ oversaw the analysis and interpretation of the data, and produced the initial and final manuscript. TC conducted the statistical analyses and assisted in interpreting the findings. DS contributed to the design of the Vietnameseimmigrant and Mekong Delta Vietnamese surveys, interpretation of analyses, and to the development of the manuscript. TTBP conducted and managed the Vietnamese surveys reported. MGN contributed to the design and acquisition of the Mekong Delta Vietnamese survey. ZS conceptualized the design and oversaw the implementation of the Vietnamese-immigrant and Mekong Delta Vietnamese surveys, and was substantially involved in the production of the manuscript. All authors have read and approved the final manuscript.

\section{Acknowledgements}

The authors wish to thank the participants in the community surveys reported in this study, and the mental health interview teams who administered the surveys across settings.

\section{Funding}

This research was supported in part by an Australian National Health and Medical Research Council Program Grant (300304).

\section{Author details}

'Psychiatry Research and Teaching Unit (PRTU), School of Psychiatry, University of New South Wales, Sydney, Australia. ${ }^{2}$ School of Psychology, University of New South Wales, Sydney, Australia. ${ }^{3}$ Centre for Population Mental Health Research, Level 1, Mental Health Centre, Liverpool Hospital, Sydney, Australia. ${ }^{4}$ Department of Psychiatry, Cần Thơ University, Cần Thơ, Vietnam.

Received: 15 November 2012 Accepted: 19 November 2013 Published: 2 December 2013

\section{References}

1. WHO International Consortium in Psychiatric Epidemiology: Cross-national comparisons of the prevalences and correlates of mental disorders. Bull World Health Organ 2000, 78:413-426.

2. Kessler R, Aguilar-Gaxiola S, Alonso J, Chatterji S, Lee S, Ormel J, Ustun TB, Wang PS: The global burden of mental disorders: an update from the WHO World Mental Health (WMH) surveys. Epidemiol Psichiatr Soc 2009, 18:23-33.

3. The WHO World Mental Health Survey Consortium: Prevalence, severity, and unmet need for treatment of mental disorders in the world health organization world mental health surveys. JAMA 2004, 291:2581-2590.
4. Shrout PE, Canino GJ, Bird HR, Rubio-Stipec M, Bravo M, Burnam MA: Mental health status among Puerto Ricans, Mexican Amercians and non-hispanic whites. Am J Community Psychol 1992, 20:729-752.

5. Vega WA, Kolody B, Agilar-Gaxiola S, Alderete E, Catalano R, Caraveo-Anduaga $\mathrm{J}$ : Lifetime prevalence of DSM-III-R psychiatric disorders among Urban and Rural Mexican Americans in California. Arch Gen Psychiatry 1998, 55:771-778.

6. Breslau J, Aguilar-Gaxiola S, Borges G, Kendler KS, Su M, Kessler RC: Risk for psychiatric disorder among immigrants and their US-born descendants: evidence from the national comorbidity survey replication. J Nerv Ment Dis 2007, 195:189-195.

7. Steel Z, Silove D, Gaio NM, Thi Bich Pahn T, Chey T, Whelen A, Bauman A, Bryant RA: International and indigenous diagnoses of mental disorder among Vietnamese living in Vietnam and Australia. Br J Psychiatry 2009, 194:326-333.

8. Kessler RC: Epidemiology of women and depression. J Affect Disord 2003, 74:5-13.

9. Uutela A: Economic crisis and mental health. Curr Opin Psychiatry 2010, 23:127-130.

10. Borges G, Nock MK, Haro Abad JM, Hwang I, Sampson NA, Alonso J, Andrade $\mathrm{LH}$, Angermeyer MC, Beautrais A, Bromet $\mathrm{E}$, et al: Twelve-month prevalence of and risk factors for suicide attempts in the world health organization world mental health surveys. J Clin Psychiatry 2010, 71:1617-1628.

11. Jorm AF: Does old age reduce the risk of anxiety and depression? A review of epidemiological studies across the adult life span. Psychol Med 2000, 30:11-20.

12. Otsuki TA: Substance use, self-esteem, and depression among Asian American adolescents. J Drug Educ 2003, 33:369-390.

13. Breslau J, Borges G, Hagar Y, Tancredi D, Gilman S: Immigration to the USA and risk for mood and anxiety disorders: variation by origin and age at immigration. Psychol Med 2009, 39:1117-1127.

14. Evans DL, Charney DS, Lewis L, Golden RN, Gorman JM, Krishnan KR, Nemeroff CB, Bremner JD, Carney RM, Coyne JC, et al: Mood disorders in the medically ill: scientific review and recommendations. Biol Psychiatry 2005, 58:175-189.

15. Steel Z, Chey T, Silove D, Marnane C, Bryant RA, von Ommeren M: Association of Torture and Other Potentially Traumatic Events With Mental Health Outcomes Among Populations Exposed to Mass Conflict and Displacement: A Systematic Review and Meta-analysis. JAMA 2009, 302:537-549.

16. Mollica RF, Mclnnes K, Pool C, Tor S: Dose-effect relationships of trauma to symptoms of depression and post-traumatic stress disorder among Cambodian survivors of mass violence. Br J Psychiatry 1998, 173:482-488.

17. Patel V, Kleinman A: Poverty and common mental disorders in developing countries. Bull World Health Organ 2003, 81:609-615.

18. Lewis-Fernandez R, Hinton DE, Laria AJ, Patterson EH, Hoffman SG, Craske MG, Stein DJ, Asnaani A, Liao B: Culture and Anxiety Disorders: Recommendations for DSM-V. Depress Anxiety 2009, 0:1-18.

19. Breslau J, Aguilar-Gaziola S, Kendler KS, Su M, Williams DR, Kessler RC: Specifying race-ethnic differences in risk for psychiatric disorder in a USA national sample. Psychol Med 2006, 36:57-68.

20. Collins PY, Patel V, Joestl SS, March D, Insel TR, Daar AS, Anderson W, Dhansay MA, Phillips A, Shurin S, Walport M, et al: Grand challenges in global mental health. Nature 2011, 475:27-30.

21. Patel V: Cultural factors and international epidemiology. Br Med Bull 2001, 57:33-45.

22. Lee S, Tsang A, Zhang M-Y, Huang Y-Q, He Y, Liu Z-R, Shen Y, Kessler RC: Lifetime prevalence and inter-cohort variation in DSM-IV disorders in metropolitan China. Psychol Med 2007, 37:61-71.

23. Wittchien H-U, Robins LN, Cottler LB, Sartorius N, Burke JD, Regier D: Cross cultural Feasibility, Reliability and Sources of Variance of the Composite International Diagnostic Interview (CIDI). Br J Psychiatry 1991, 159:645-653.

24. Andrews $G$, Peters $L$ : The psychometic properties of the Composite International Diagnostic Interview. Soc Psychiatry Psychiatr Epidemiol 1998, 33:80-88

25. Kessler RC, Üstün TB: The World Mental Health (WMH) Survey Initiative Version of the World Health Organization (WHO) Composite International Diagnostic Interview (CIDI). Int J Methods Psychiatr Res 2004, 13:93-121.

26. Phan T, Steel Z, Silove D: An ethnographically derived measure of anxiety, depression and somatization: the Phan Vietnamese psychiatric scale. Transcult Psychiatry 2004, 41:200-232. 
27. Steel Z, Silove D, Chey T, Bauman A, Phan T: Mental disorders, disability and health service use amongst Vietnamese refugees and the host Australian population. Acta Psychiatr Scand 2005, 111:300-309.

28. Mollica R, Caspi-Yavin Y, Bollini P, Truong T, Tor S, Lavelle J: The Harvard Trauma Questionnaire; validating a cross cultural instrument for measuring torture, trauma, and post-traumatic stress disorder in Indochina refugees. J Nerv Ment Dis 1992, 180:111-116.

29. Silove D, Steel Z, Bauman A, Chey T, McFarlane A: Trauma, PTSD, and the longer-term mental health burden amongst Vietnamese refugees: A comparison with the Australian-born population. Soc Psychiatry Psychiatr Epidemiol 2007, 42:467-476.

30. Australian Bureau of Statistics (ABS): Mental health and wellbeing: profile of adults. Canberra, Australia: Australian Bureau of Statistics; 1998.

31. Bracken BA, Barona A: State of the art procedures for translating, validating and using psychoeducational tests in cross-cultural assessment. School Psychol Int 1991, 12:119-132.

32. Hosmer DW, Lemeshow S: Applied Logistic Regression. New York: Wiley \& Sons; 2000.

33. Voracek M, Loibl LM, Dervic K, Kapusta ND, Niederkrotenthaler T, Sonneck G Consistency of immigrant suicide rates in Austria with country-of-birth suicide rates: a role for genetic risk factors for suicide? Psychiatry Res 2009, 170:286-289.

34. Steel Z, Silove D, Phan T, Bauman A: Long-term effect of psychological trauma on the mental health of Vietnamese refugees resettled in Australia: a population-based study. Lancet 2002, 360:1056-1062

35. Mollica RF, Mclnnes K, Pham T, Smith Fawzi MC, Murphy E, Lien L: The dose-effect relationships between torture and psychiatric symptoms in Vietnamese ex-political Detainees and a comparison group. J Nerv Ment Dis 1998, 186:543-553.

36. Kessler RC, Birnbaum HG, Shahly V, Bromet E, Hwang I, McLaughlin KA, Sampson N, Andrade LH, De Girolamo G, Demyttenaere K, et al: Age differences in the prevalence and co-morbidity of DSM-IV major depressive episodes: results from the WHO World Mental Health Survey initiative. Depress Anxiety 2010, 27:351-364.

37. Kessler RC, Birnabaum H, Bromet E, Hwang I, Sampson N, Shahly V: Age differences in major depression: results from the National Comorbidity Survey Replication (NCS-R). Psychol Med 2010, 40:225-237.

38. Cardoso JB, Thompson SJ: Common themes of resilience among Latino immigrant families: a systematic review of the literature. Families in Society 2010, 91:257-265.

39. Parks $C D$, Vu AD: Social dilemma behavior of individuals from highly individualist and collectivist cultures. J Conflict Resol 1994, 38:708-718.

40. Lim M, Stormshak EA, Falkenstein CA: Psychosocial adjustment and substance use of Cambodian and Vietnamese immigrant youth. $J$ Cross Cult Psychol 2011, 42:104-119.

41. Kleinman AM: Depression, somatization and the "New cross-cultural" psychiatry. Soc Sci Med 1977, 11:3-10.

42. Kirmayer $\mathrm{L}$ : Culture, context and experience in psychiatric diagnosis. Psychopathology 2005, 38:192-196.

43. Alarcon RD: Culture, cultural factors and psychiatric diagnosis: review and projections. World Psychiatry 2009, 8:131-139.

44. Alarcon RD, Becker AE, Lewis-Fernandez R, Like RC, Desai P, Foulks E, Gonzales J, Hansen H, Kopelowicz A, Lu GG, et al: The role of culture in psychiatric diagnosis. J Nerv Ment Dis 2009, 197:559-560

\section{Submit your next manuscript to BioMed Central and take full advantage of:}

- Convenient online submission

- Thorough peer review

- No space constraints or color figure charges

- Immediate publication on acceptance

- Inclusion in PubMed, CAS, Scopus and Google Scholar

- Research which is freely available for redistribution

Submit your manuscript at www.biomedcentral.com/submit
C Biomed Central 